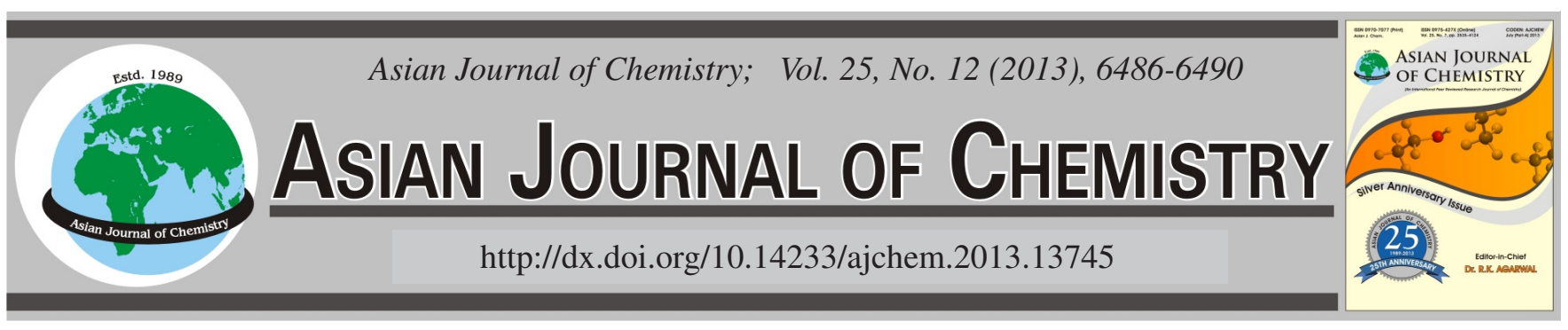

\title{
Utilization of Microfluidic Device for Determination of Nitrite and Nitrate in Water and Soil Samples
}

\author{
N. Laitip ${ }^{1}$, N. Chomnawang ${ }^{2,3}$, N. Youngvises ${ }^{4}$ and W. Threeprom ${ }^{1,5, *}$
}

${ }^{1}$ Department of Chemistry and Center of Excellence for Innovation in Chemistry, Faculty of Science, Mahidol University, Rajathewi, Bangkok 10400, Thailand

${ }^{2}$ School of Electrical Engineering, Institute of Engineering, Suranaree University of Technology, Suranaree, Muang District, Nakhon Ratchasima 30000, Thailand

${ }^{3}$ The Siam Photon Laboratory of the Synchrotron Light Research Institute, Suranaree, Muang District, Nakhon Ratchasima 30000, Thailand ${ }^{4}$ Department of Chemistry, Faculty of Science and Technology, Thammasat University, Rangsit Center, Pathum Thani 12121, Thailand

${ }^{5}$ Interdisciplinary Division, Mahidol University, Kanchanaburi Campus, Kanchanaburi 71150, Thailand

*Corresponding author: Fax: +66 34 585077; Tel: +66 34585059 ext. 2136; E-mail: wthreeprom@yahoo.com

\begin{abstract}
A miniaturized system for determination of nitrite and nitrate by microfluidic device with chemiluminescence detection has been described. This method is based on chemiluminescence reaction produced by oxidation of nitrite with hydrogen peroxide in acid medium in the presence of alkaline luminol. The sequential determination of nitrite and nitrate utilized an off-line photolytic reduction of nitrate to nitrite was applied incorporating with EDTA as an activator. Efficiency of the photo-conversion was satisfactory good with $47-52 \%$ of conversion. The optimized condition provided a linearity range between $0.5-100 \mu \mathrm{M}$ for nitrite and $1.0-100 \mu \mathrm{M}$ for nitrate. The detection limit for nitrite and nitrate were $2.1 \times 10^{-2} \mu \mathrm{M}$ and $9.3 \times 10^{-2} \mu \mathrm{M}$, respectively. The precision of the method was satisfactory good with \% RSD of $5 \mu \mathrm{M}$ of nitrite and $10 \mu \mathrm{M}$ of nitrate were less than 3.3 and $3.6 \%$, respectively $(\mathrm{n}=10)$. The potential ion interferences namely $\mathrm{Fe}^{2+}, \mathrm{Fe}^{3+}$, $\mathrm{Cu}^{2+}$ and $\mathrm{Mn}^{2+}$ were completely eliminated by on-line passing through the samples on cation exchange column. This proposed method was successfully applied for quantitative analysis of nitrite and nitrate in environmental water samples and agricultural soil samples with desirable recovery ranging from 85 to $110 \%$.
\end{abstract}

Key Words: Nitrite, Nitrate, Microfluidic device, Chemiluminescence, Water, Soil.

\section{INTRODUCTION}

Nitrate and nitrite species are naturally occur in typically environment and are part of the nitrogen cycle. They represent wide spread contaminants in the environment and important serve to evaluate quality of natural water ${ }^{1}$. Naturally occurring nitrate levels in surface and ground waters are generally a few $\mathrm{mg} / \mathrm{L}$. In many ground waters, an increase of nitrate levels has been observed due to the excess application of nitrogen fertilizers of farming practice ${ }^{2}$. In some countries, up to $10 \%$ of the pollution may be exposed to nitrate levels in drinking water of above $50 \mathrm{mg} / \mathrm{L}$. As recently found in 2007, the Greenpeace Research Group has reported the nitrate levels found in agricultural areas in Thailand. Drinking water from $30 \%$ of all groundwater wells in investigated areas showed high content of nitrates which are 3 times above the World Heath Organization (WHO) safety limit of $50 \mathrm{mg} / \mathrm{L}$ of nitrate. This nitrate pollution was highest in the most intensive crops, in asparagus farms in Kanchanaburi ${ }^{3}$. High levels of nitrate and nitrite thus pose a threat to human health. The high levels of nitrate could have health effects such as diabetes, diarrhoea, abdominal pain and muscle weakness. In addition, nitrate can transform to nitrite in the digestive system. For nitrite, the primary health concern is the formation of methaemoglobinaemia or blue-baby syndrome. The secondary widely concern is the reaction with amines to form carcinogenic nitrosamines in the stomach ${ }^{4}$. Excessive concentrations of nitrate and nitrite in drinking water can be hazardous to health. Therefore, the U.S. Environmental Protection Agency (USEPA) has set the maximum contamination level or MCL for nitrate and nitrite at 44.3 and $3.3 \mathrm{mg} / \mathrm{L}$, respectively while the MCL set by WHO for nitrate and nitrite are 50 and $5 \mathrm{mg} /$ $\mathrm{L}$, respectively.

With regard to the nitrite-nitrate problem, a test with the sensitive analytical method is highly recommended. Many methods including chromatography ${ }^{5,6}$, flow injection analysis ${ }^{7,8}$, electrochemistry ${ }^{9}$, electrophoresis ${ }^{10,11}$ and UV-VIS spectrophotometry $^{12-15}$ are commonly employed. Unfortunately, some of 
these methods have disadvantages of the use of toxic reagents, requiring large reagent volume, complication of preparation process, poor reproducibility, expensive and time consuming. Therefore an alternative method provided advantages of being portable, low reagent consumption, short analysis time and simple operation is sought for laboratory test ${ }^{16}$. Hence a new trend of miniaturized system might be matched with exact purpose. For that reason a miniaturized system is potentially become as an attractive candidate.

A detection modes in the miniaturized system are varied. Chemiluminescence (CL) provides high sensitivity and wide dynamic range, simple and inexpensive instrumentation is dramatically considered as detection method ${ }^{17}$. Based on advantages of chemiluminescence detection, Mikuška and Vecera $^{18}$ recently reported the use of chemiluminescence technique for nitrite analysis relied on the oxidation of luminol with peroxynitrous acid. Low limit of detection at $2.0 \mathrm{nM}$ of nitrite can be achieved. The nitrate determination can also be performed based upon photolytic nitrate reduction. The limit of detection at $4.0 \mathrm{nM}$ of nitrate was obtained.

With new trend of technology, a miniaturized system in shape of microfluidic device integrated with chemiluminescence method will be firstly proposed for determination of nitrate and nitrite in this work. The sequential determination of nitrate and nitrite by photolytic reduction will be performed. The contents of nitrate and nitrite in water and soil samples will be monitored.

\section{EXPERIMENTAL}

All chemicals were of analytical grade and all solutions were prepared throughout in deionized distilled water which was purified with a milli-Q system (Millipore, USA). All solutions were stored in refrigerator at $4{ }^{\circ} \mathrm{C}$ before used. Standard stock solutions of nitrate and nitrite $\left(0.01 \mathrm{M} \mathrm{NO}_{3}^{-}\right.$ and $0.01 \mathrm{M} \mathrm{NO}_{2}^{-}$) were prepared from sodium nitrate and sodium nitrite (Ajex, Australia), respectively.

A chemiluminescence reagent solution, luminol (Fluka, Russian) is pure and used without further purification. Luminol stock standard solution was prepared in sodium hydroxide (Merck, Germany). An oxidizing reagent solution is prepared from $30 \%$ hydrogen peroxide (Merck, Germany) in hydrochloric acid (Merck, Germany). Disodium salt-EDTA (Fisher, Germany) is prepared in deionized distilled water.

An extraction solution for soil analysis, $2.0 \mathrm{M} \mathrm{KCl}$ (Merck, Germany) was prepared in deionized water.

The cation exchange column $(1 \mathrm{~cm}$ length, $0.5 \mathrm{~cm}$ i.d. PTFE tube) is packed with $\mathrm{H}^{+}$form Dowex $50 \mathrm{~W}$ cation exchange resin (50-100 mesh, capacity 0.7 meq./mL) (Fluka, Russian). Each end of the column is plugged by a glass wool.

The employed microfluidic system was illustrated in Fig. 1. The system comprised with the syringe pump (model LSPO02 - 1B, Longer precision pump Co. Ltd., China) which used to control all reagent solutions through PTFE tubes $(0.75$ $\mathrm{mm}$ i.d.) and a 6-port rotary injection valves (E60CE, VALCO Instrument Co. Inc., USA) to inject standard and sample into the system. The chemiluminescence signal was detected and recorded by a photomultiplier tube (PMT) (Thorn-EMI 9878SB, Electron Tubes Ltd., UK) which was operated at
$860 \mathrm{~V}$ by a power supply (Thorn-EMI model PM20D, Electron Tubes Ltd., UK). The signal was demonstrated via a home-made computer program. The microfluidic device was placed in the black box all times.

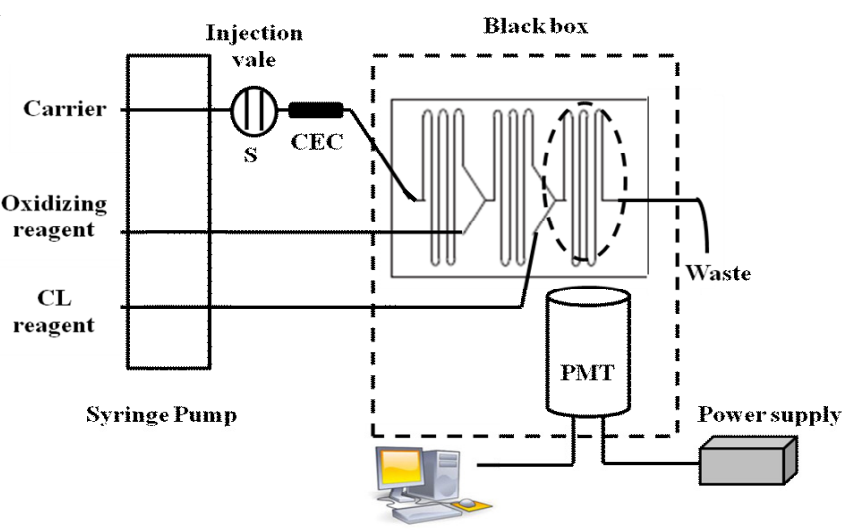

Fig. 1. A scheme of the microfluidic system for determination of nitrite and nitrate in water and soil samples where $\mathrm{S}$ : standard or sample, Carrier: $\mathrm{H}_{2} \mathrm{O}$, Oxidizing reagent: $\mathrm{H}_{2} \mathrm{O}_{2}-\mathrm{HCl}$, chemiluminescence reagent: Luminol-NaOH, CEC: Cation exchange column

For nitrate conversion, an off-line conversion was used. A UV-254 nm, $8 \mathrm{~W}$ lamp was employed as a UV radiation source in the home-made box.

\section{General procedure}

Fabrication of the microfluidic device: The simple microfluidic device (Fig. 2) was kind of poly(dimethylsiloxane) (PDMS) platform. It was produced from two small pieces of PDMS slice $(3 \mathrm{~cm} \times 4 \mathrm{~cm})$. One piece contained microchannel while another was bared piece. The microfluidic channel was fabricated from the technological core of LIGA which is $\mathrm{X}$-ray lithography with synchrotron radiation (SR). In brief, the microfluidic master template is firstly produced by LIGA lithography. Secondly the microchannel is molded and peeled off from the template. Master template fabrication is consisted of 2 processes that are X-ray mask preparation process and LIGA process. In first process, an X-ray mask was fabricated by UV exposuring on coated glass substrate $(\mathrm{Cr} / \mathrm{Ag} / \mathrm{Cr}$ which double coated with SU-8) through a UV photomask of microchannels layout. After development of this substrate, a positive surface microchannel structure was appeared on the substrate. Next, it was plated using Ag electroplating resulted in Ag X-ray mask. In second process, LIGA technique was done for making of microfluidic mastermold. It was fabricated by X-ray synchrotron exposuring on SU-8 coated glass substrate through the Ag X-ray mask of microchannels layout. After development, the positive micro channel was shown on mastermold. The mastermold was then used for PDMS molding. In molding process, PDMS base and curing agent (Sylgard 184, Wiesbaden, Germany) were mixed with ratio $10: 1$, respectively. It was degassed and poured on to the mastermold platform and then baked at $80^{\circ} \mathrm{C}$ for $1 \mathrm{~h}$. Afterthat, the PDMS slice was peeled off from the mastermold. The obtained microchannel was smooth and showed the fine dimension of $150 \mu \mathrm{m}$ wide and $100 \mu \mathrm{m}$ deep (Fig. 2). For bonding of PDMS microfluidic device, the method was adapted from Eddings et al. ${ }^{19}$. The contained microchannel PDMS slice 


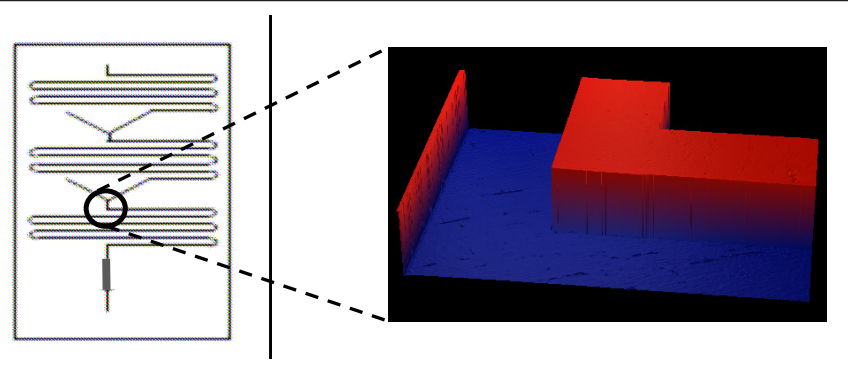

(a)

(b)

Fig. 2. (a) Schematic diagram of employed microchannel pattern. (b) The dimension of microchannels was $150 \mu \mathrm{m}$ wide and $100 \mu \mathrm{m}$ deep

and bared PDMS slice were pre-cured at $60^{\circ} \mathrm{C}$ for $35 \mathrm{~min}$ and then were placed together and fully cured overnight for bonding. The entire channels were drilled and connected with tubing.

Sample preparation: The water samples namely tap water, groundwater and natural water were collected in agricultural area from pineapple farm (Prachuapkhirikhan, Thailand) and preserved with diluted sulfuric acid before the analysis. Drinking water, river water and rainwater were collected in Bangkok, Thailand and analyzed within $24 \mathrm{~h}$ without preservation. All of water samples were filtered through $0.45 \mu \mathrm{m}$ membrane filters before the analysis.

Soil samples were also taken from agricultural area in Prachuapkhirikhan, Thailand and were air-dried for $24 \mathrm{~h}$. Afterthat, they were ground and sieved to $2 \mathrm{~mm}$ particle size and then extracted with $\mathrm{KCl}^{20}$. Approximately $5 \mathrm{~g}$ of dried soil sample was placed in polypropylene copolymer centrifuge tubes containing $50 \mathrm{~mL}$ of $2.0 \mathrm{M} \mathrm{KCl}$. The suspension was shaken for $90 \mathrm{~min}$ and then centrifuged. The clear supernatant was used for the analysis.

Detection method: The instrumentation was depicted in Fig. 1. The syringe pump was used to propel all reagents and carrier stream throughout the determination with the constant flow rate at $110 \mu \mathrm{L} / \mathrm{min}$. Before starting the analysis cycle, all solutions namely deionized distilled water, oxidizing agent and luminol were filled in the tubing by syringe pump. After the chemiluminescence background of this system was stable, the $100 \mu \mathrm{L}$ of standard or sample solution was loaded into the sample loop and injected into the carrier stream by injection valve. The solutions were then merged with the oxidizing agent stream which is hydrogen peroxide in acidic medium to produced peroxynitrous acid. Finally, the produced acid was merged into chemiluminescence reagent which is luminol solution in basic medium in mixing channel resulting in emitted chemiluminescence signal at the detection area.

For the determination of nitrate, the off-line photoconversion was used to convert nitrate to nitrite before the analysis. After that total nitrite was detected by the procedure described above. The nitrate content was determined by the difference of contents between total nitrite and nitrite.

\section{RESULTS AND DISCUSSION}

Optimization of flow rate: The influences of the carrier and reagent flow rate of $10 \mu \mathrm{M}$ nitrite standard solution on chemiluminescence reaction were investigated in the range of $50-150 \mu \mathrm{L} / \mathrm{min}$. The gradually increased of chemiluminescence intensity was observed until the flow rate reached 110 $\mu \mathrm{L} / \mathrm{min}$. At higher flow rate the decreased of chemiluminescence intensity was shown due to the uncatchable chemiluminescence signal. A flow rate of $110 \mu \mathrm{L} / \mathrm{min}$ was finally adopted as the optimal flow rate and used throughout this work.

Optimization of nitrate photoreduction: For reduction of nitrate to nitrite, a variety of reducing agents has been reported to facilitate nitrate conversion to nitrite like zinc ${ }^{21}$, hydrazine $^{22}$, cadmium $^{23}$ and copper-coated cadmium ${ }^{24,25}$. The latter is the most often used as a result of nearly $100 \%$ conversion efficiency. However, it is difficult to prepare reproducibly cadmium with constant properties and maintain its efficiency over a sufficiently long time period ${ }^{18}$. In addition, cadmium has toxic and carcinogenic property. It is evident that non toxic alternatives are need for nitrate reduction which involves a photolytic conversion by absorption of UV light according to a simple stoichiometric equation ${ }^{26,27}$.

Nitrate shows a UV absorption with between 201-302 $\mathrm{nm}^{26}$. The efficiency of nitrate conversion depends on various factors such as residence time of conversion, the presence of EDTA as an activator and $\mathrm{pH}$ of the solution. In this work the UV irradiation at $254 \mathrm{~nm}$ was applied for conversion and pre-tested with off-line method.

The effect of the UV irradiation time was examined over the range of 1-30 min. The signal was increased when the residence time was increased and gave a highest signal at 20 min. The signal was constant over the longer residence time. Therefore, an irradiation time of 20 min was selected for conversion. Since the contact time is quite long, the on-line reduction might be mismatched for this work. Therefore, the off-line protocol was applied. However, the contact time might be decreased if the high power of UV lamp can be adopted ${ }^{8,26}$.

The effect of an activator for nitrate reduction was carried out by using EDTA. Agreement with other reports was observed $^{26-28}$. The intensity was dramatically improved in the adding of activator. The maximum reduction efficiency was achieved with $10 \mathrm{mM}$ EDTA.

The reported maximum yield of nitrate photo-reduction was achieved in the alkaline region ${ }^{26,28}$. Therefore, $\mathrm{pH}$ of nitrate solution was investigated in the range 7-12. The efficiency of nitrate conversion increased with increasing the $\mathrm{pH}$ and the maximum chemiluminescence intensity was obtained at $\mathrm{pH} 10$.

The optimized conditions for nitrate photo-reduction are summarized in Table-1. The conversion efficiency was reached to $47-52 \%$ as described elsewhere ${ }^{26,28}$.

\begin{tabular}{ccc}
\multicolumn{4}{c}{ TABLE-1 } \\
\multicolumn{3}{c}{ SUMMARY OF PARAMETERS USED IN OFF-LINE } \\
& NITRATE PHOTO-REDUCTION \\
\hline Parameters & Studied range & Optimum condition \\
\hline EDTA $(\mathrm{mM})$ & $1-30$ & 10 \\
Time $(\mathrm{min})$ & $0-30$ & 20 \\
$\mathrm{pH}$ & $7-12$ & 10 \\
\hline
\end{tabular}

Optimization of the chemiluminescence microfluidic system: For chemiluminescence reaction, the formation of peroxynitrous acid is produced from the reaction between nitrite and hydrogen peroxide in acidic medium and is quenched into peroxynitrite in alkaline solution in the presence of luminol 
resulted in emitted chemiluminescence signal ${ }^{29}$. The determination of nitrite and nitrate could be conducted by the same strategy after nitrate was converted to nitrite. Therefore, several chemical parameters affected on the sensitivity were studied by injections of $10 \mu \mathrm{M}$ of nitrite standard solution at constant flow rate of $110 \mu \mathrm{L} / \mathrm{min}$. The optimization process was investigated by simplex optimization method.

The initial simplex conditions employed were started from an oxidizing agent stream of $5 \mathrm{mM} \mathrm{H}_{2} \mathrm{O}_{2}$ in $0.50 \mathrm{M} \mathrm{HCl}$, a chemiluminescence reagent stream of $0.60 \mathrm{M}$ luminol in $3 \mathrm{mM}$ $\mathrm{NaOH}$. The improvement of sensitivity became insignificant within 28 steps and then simplex procedure was stopped. In this case, the response started out relatively low and increased rapidly, then swingier and provided the best chemiluminescence intensity at vertex number 21 , finally stabilized at approximately vertex number 28 . The optimal values achieved by the simplex methods were described with the following parameters' values: $\mathrm{H}_{2} \mathrm{O}_{2} 7.33 \mathrm{mM}, \mathrm{HCl} 9.81 \mathrm{M}$, luminol 3.68 $\mathrm{mM}$ and $\mathrm{NaOH} 1.08 \mathrm{M}$.

Analytical performance: The analytical performance of the proposed method was evaluated under the above optimal condition. The employed reaction provided the linearity range of nitrite over from $0.5-100 \mu \mathrm{M}\left(\mathrm{y}=20.65 \mathrm{x}-1.96 ; \mathrm{r}^{2}=0.9970\right)$ while linearity range of nitrate was in the range of 1.0-100 $\mu \mathrm{M}\left(\mathrm{y}=10.57 \mathrm{x}-10.69 ; \mathrm{r}^{2}=0.9959\right)$. A chemiluminescence signal of calibration curve is shown in Fig. 3. The limit of detection $(\mathrm{LOD})(\mathrm{S} / \mathrm{N}=3)$ of nitrite and nitrate were $2.1 \times 10^{-2}$ and $9.3 \times 10^{-2} \mu \mathrm{M}$, respectively. This LOD was superior lower than the MCL values in regulation set by WHO and USEPA for nitrite and nitrate level in drinking water. Therefore this method could be used to determine nitrite and nitrate in water samples.

The precision of this method was evaluated as the relative standard deviations of repetitive injection $(\mathrm{n}=10)$ of $50 \mu \mathrm{M}$ nitrite and nitrate standard solution and was 3.3 and $3.6 \%$, respectively.

Effect of interferences: From the procedure, the effect of the foreign ions generally presented in water and soil sample on the chemiluminescence intensity was studied. The interfe-

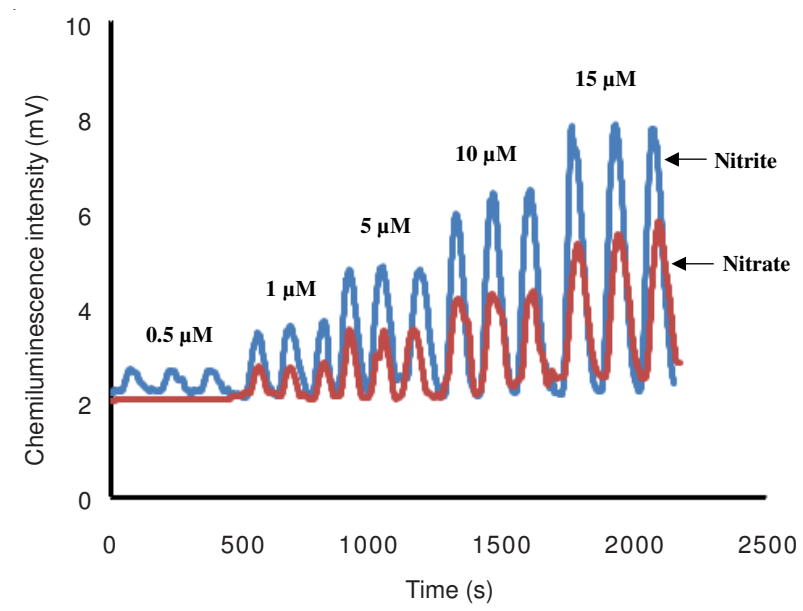

Fig. 3. Typical chemiluminescence intensity of calibration curve for nitrite and nitrate determination in the range of 0.5 to $15 \mu \mathrm{M}$

rence ions were added to standard of $10 \mu \mathrm{M}$ nitrite. An error at least $\pm 5 \%$ on the chemiluminescence signal was considered to be tolerable. Results are summarized in Table-2.

TABLE-2

TOLERABLE CONCENTRATION RATIO WITH RESPECT TO $10 \mu \mathrm{M}$ NITRITE FOR SOME OF FOREIGN IONS

\begin{tabular}{lcc}
\hline \multicolumn{1}{c}{ Foreign ions } & \multicolumn{2}{c}{$\begin{array}{c}\text { Tolerable concentration ratio } \\
{[\text { foreign ion] } /[\text { nitrite] }}\end{array}$} \\
\cline { 2 - 3 } & Without CEC & With CEC $^{\mathrm{b}}$ \\
\hline $\mathrm{Fe}^{2+}, \mathrm{Fe}^{3+}$ & 0.01 & 10 \\
$\mathrm{Mn}^{2+}, \mathrm{Cu}^{2+}$ & 1 & 100 \\
$\mathrm{Ca}^{2+}, \mathrm{NH}_{4}^{+}, \mathrm{Mg}^{2+}$, & 50 & 500 \\
$\mathrm{Na}^{+}, \mathrm{Zn}^{+}, \mathrm{K}^{+}$ & 100 & 1000 \\
$\mathrm{PO}_{4}{ }^{2-}, \mathrm{SO}_{4}^{2-}, \mathrm{Cl}^{-}, \mathrm{CO}_{3}{ }^{2-}$ & 100 & - \\
\hline
\end{tabular}

${ }^{a}$ The tolerable concentration ratio was calculated for a $5 \%$ signal change; ${ }^{\mathrm{b}} \mathrm{CEC}$ means cation exchange column.

The typically anionic ions have no effect on the determination. However, The presence of some cationic ions were effected seriously on chemiluminescence intensity especially for $\mathrm{Fe}^{2+}, \mathrm{Fe}^{3+}, \mathrm{Cu}^{2+}$ and $\mathrm{Mn}^{2+}$ which produced a strongly chemiluminescence intensity due to the decomposition of $\mathrm{H}_{2} \mathrm{O}_{2}$

TABLE-3

CONTENTS OF NITRITE AND NITRATE IN VARIOUS KINDS OF WATER SAMPLES

\begin{tabular}{|c|c|c|c|c|}
\hline \multirow{2}{*}{ Sample } & \multicolumn{2}{|c|}{ Concentration of nitrite $^{\mathrm{a}}(\mu \mathrm{M})$} & \multicolumn{2}{|c|}{ Concentration of nitrate $^{\mathrm{a}}(\mu \mathrm{M})$} \\
\hline & Proposed method & Reference method & Proposed method & Reference method \\
\hline \multicolumn{5}{|l|}{ Drinking water } \\
\hline Sample 1 & n.d. ${ }^{\text {b }}$ & n.d. & $3.39 \pm 0.14$ & $3.27 \pm 0.58$ \\
\hline Sample 2 & n.d. & n.d. & $4.97 \pm 0.38$ & $4.75 \pm 0.11$ \\
\hline \multicolumn{5}{|c|}{ Mineral drinking water } \\
\hline Sample 1 & n.d. & n.d. & $5.90 \pm 0.42$ & $5.73 \pm 0.58$ \\
\hline Sample 2 & n.d. & n.d. & $5.00 \pm 0.94$ & $4.88 \pm 0.11$ \\
\hline \multicolumn{5}{|l|}{ Natural water } \\
\hline Sample 1 & $1.30 \pm 0.38$ & $1.28 \pm 0.40$ & $36.9 \pm 10$ & $35.4 \pm 8.9$ \\
\hline Sample 2 & $1.75 \pm 0.44$ & $1.65 \pm 0.52$ & $63.0 \pm 12$ & $62.6 \pm 11$ \\
\hline Sample 3 & $1.74 \pm 0.48$ & $1.83 \pm 0.43$ & $53.8 \pm 28$ & $53.4 \pm 11$ \\
\hline Sample 4 & $1.56 \pm 0.45$ & $1.43 \pm 0.20$ & $48.3 \pm 22$ & $48.9 \pm 9.5$ \\
\hline Tap water & n.d. & n.d. & $27.7 \pm 2.9$ & $28.3 \pm 0.58$ \\
\hline Rain water & $1.64 \pm 0.21$ & $1.40 \pm 0.10$ & $13.1 \pm 0.63$ & $12.8 \pm 0.58$ \\
\hline River water & $0.57 \pm 0.06$ & $0.55 \pm 0.12$ & $31.9 \pm 1.6$ & $31.7 \pm 3.1$ \\
\hline Ground water & $1.44 \pm 0.31$ & $1.36 \pm 0.13$ & $75.8 \pm 7.1$ & $77.4 \pm 6.9$ \\
\hline
\end{tabular}

${ }^{\mathrm{a}}$ Mean for three determination \pm S.D.; ${ }^{\mathrm{b}}$.d. means for not detected. 
catalyzed by transition metals ${ }^{4}$. These interferences could be successfully removed by the cation exchange column which was placed in front of microfluidic device.

Analysis of real sample: The developed method was applied for the analysis of nitrite and nitrate in various kinds of water samples and soil samples. The results in Tables 3 and 4 showed the contents of nitrite and nitrate in various kinds of tested samples. The accuracy of the tested method was compared with the standard method which is the spectrophotometric method based on Griss reaction ${ }^{30}$. The evaluation by paired t-test method at $95 \%$ confidence level indicates that the results obtained by the proposed method agreed well with those obtained by the standard method. The recovery tests were made with 12 water samples and five soil samples by addition of $10 \mu \mathrm{M}$ of nitrite and nitrate. The recoveries of real water samples for nitrite were found in the range of 92-108\% while the recoveries of nitrate in water samples were between 85 $110 \%$. The recoveries of nitrite and nitrate in soil samples were between 88-110 and 95-109\%, respectively.

\begin{tabular}{lrc|rr}
\multicolumn{4}{c}{ TABLE-4 } \\
& \multicolumn{2}{c}{$\begin{array}{c}\text { CONTENTS OF NITRITE AND NITRATE IN } \\
\text { AGRICULTURAL SOIL SAMPLES }\end{array}$} \\
\hline & \multicolumn{2}{c}{$\begin{array}{c}\text { Concentration of }^{\text {nitrite }}(\mu \mathrm{M}) \\
\text { Sample }\end{array}$} & \multicolumn{2}{c}{$\begin{array}{c}\text { Concentration of } \\
\text { nitrate }\end{array}$} \\
\cline { 2 - 5 } & \multicolumn{2}{c}{$\mu \mathrm{M})$} \\
\cline { 2 - 5 } & \multicolumn{1}{c}{$\begin{array}{c}\text { Proposed } \\
\text { method }\end{array}$} & $\begin{array}{c}\text { Reference } \\
\text { method }\end{array}$ & \multicolumn{1}{|c}{$\begin{array}{c}\text { Proposed } \\
\text { method }\end{array}$} & \multicolumn{1}{c}{$\begin{array}{c}\text { Reference } \\
\text { method }\end{array}$} \\
\hline Sample 1 & $10.50 \pm 1.73$ & $10.18 \pm 1.98$ & $29.94 \pm 5.26$ & $28.21 \pm 4.59$ \\
Sample 2 & $6.99 \pm 1.97$ & $7.29 \pm 0.96$ & $81.62 \pm 17.67$ & $83.19 \pm 16.97$ \\
Sample 3 & $7.04 \pm 0.95$ & $7.76 \pm 0.91$ & $247.30 \pm 30.41$ & $231.45 \pm 27.91$ \\
Sample 4 & $10.21 \pm 0.22$ & $8.65 \pm 0.72$ & $180.69 \pm 44.68$ & $182.06 \pm 43.70$ \\
Sample 5 & $10.57 \pm 1.11$ & $9.21 \pm 0.97$ & $51.01 \pm 13.71$ & $54.83 \pm 16.26$ \\
Sample 6 & $9.04 \pm 0.89$ & $8.88 \pm 0.97$ & $73.99 \pm 17.78$ & $76.66 \pm 20.78$ \\
Sample 7 & $9.36 \pm 2.11$ & $8.18 \pm 1.63$ & $405.18 \pm 61.72$ & $392.27 \pm 43.70$ \\
\hline
\end{tabular}

${ }^{\mathrm{a}}$ Mean for three determination \pm S.D.

\section{Conclusion}

The developed microfluidic chemiluminescence method for the sensitive determination of nitrite and nitrate was described. The use of UV photoreduction for nitrate determination gave a benefit in non-toxic waste of reaction and acceptable of the conversion efficiency. The microfluidic integrated with chemiluminescence detection system can be used as an alternative method for analysis of nitrite and nitrate in wide varieties of water and soil samples with satisfactory results. With recent technology, the system might be developed for on field detection.

\section{ACKNOWLEDGEMENTS}

Financial support from the Center of Excellence for Innovation in Chemistry (PERCH-CIC), Commission on Higher Education, Ministry of Education is gratefully acknowledged. This research project is supported by Mahidol University, Bangkok, Thailand

\section{REFERENCES}

1. M.T. Fernández-Argüelles, B. Cañabate, J.M. Costa Fernández, R. Pereio and A. Sanz-Medel, Talanta, 62, 991 (2004).

2. J.A.T. Pennington, Food Control, 9, 385 (1998).

3. http://www.greenpeace.org/seasia/ph/News/news-stories/drinking-waterin-ben guet-bul

4. C. Lu, F. Qu, J.M. Lin and M. Yamada, Anal. Chim. Acta, 474, 107 (2002).

5. D. Connolly and B. Paull, Anal. Chim. Acta, 441, 53 (2001).

6. I.M.P.L.V.O. Ferreira and S. Silva, Talanta, 74, 1598 (2008).

7. A. Kazemzadeh and A.A. Ensafi, Microchem. J., 69, 159 (2001).

8. T. Aoki and M. Watabayashi, Anal. Chim. Acta, 308, 308 (1995).

9. J.H. Pei and X.Y. Li, Talanta, 51, 1107 (2000).

10. M.C.B. Alonse and R. Prego, Anal. Chim. Acta, 416, 21 (2000).

11. A.A. Okemgbo, H.H. Hill, W.F. Siems and S.G. Metealf, Anal. Chem., 71, 2725 (1999).

12. G. Norwitz and P.N. Kelliher, Analyst, 110, 689 (1985).

13. P.K. Tarafder and D.P.S. Rathore, Analyst, 113, 1073 (1988).

14. H.P.S. Rathore and S.K. Tiwari, Anal. Chim. Acta, 242, 225 (1991).

15. K. Higuchi and S. Motomizu, Anal. Sci., 15, 129 (1999).

16. D. He, Z. Zhand, Y. Huang and Y. Hu, Food Chem., 101, 667 (2007).

17. F.J. Lara, A.M. García-Campaña and J.J. Aaron, Anal. Chim. Acta, 679, 17 (2010).

18. P. Mikuska and Z. Vecera, Anal. Chim. Acta, 495, 225 (2003).

19. M.A. Eddings, M.A. Johnson and B. K. Gale, J. Micromech. Microeng., 18, 067001 (2008).

20. C.E. López-Pasquali, P. Fernándes-Hernando and J.S. Durand-Alegría, Anal. Chim. Acta, 600, 177 (2007).

21. T.J. Chow and M.S. Johnstone, Anal. Chim. Acta, 27, 441 (1962).

22. M.T. Oms, A. Cerda and V. Cerda, Anal. Chim. Acta, 315, 321 (1995).

23. J.H. Margeson, M.R. Suggs, X.C. Galhardo and C. Masini, J. Anal. Chem., 15, 1955 (1980).

24. C. Galhardo and X. Masini, Anal. Chim. Acta, 438, 39 (2001).

25. A. Kazenzadeh and A.A. Easafi, Anal. Chem., 442, 319 (2001).

26. P. Mikuska and Z. Vecera, Anal. Chim. Acta, 474, 99 (2002).

27. S. Motomizu and M. Sanada, Anal. Chim. Acta, 308, 406 (1995).

28. I. Gil-Torró, J.V. García-Mateo and J.M. Calatayud, Anal. Chim. Acta, 366, 241 (1998).

29. J.K. Robinson, M.J. Bollinger and J.W. Birks, Anal. Chem., 71, 5131 (1999).

30. APHA, Standard Methods for the Examination of the Water and Wastewater, American Public Health Association, Washington, DC, edn. 20 (1998). 